\title{
Domestic Water Sourcing and the Risk of Diarrhea: A Cross-Sectional Survey of a Peri-urban Community in Jos, Nigeria.
}

\author{
Yilgwan $\mathrm{CS}^{1}$, Yilgwan $\mathbf{G}^{2}$, Abok II $^{1}$ \\ ${ }^{\prime}$ Department of Pediatrics, Jos University Teaching Hospital, Jos \\ ${ }^{2}$ Plateau State Specialist Hospital, Jos
}

\begin{abstract}
This study examines the association between domestic water sourcing practice and the risk of developing diarrhea. A total of 200 households were studied over an eight week period spanning from $4^{\text {th }}$ June to 31 st July 2005 using an interviewer administered questionnaire.

Most of the household (80\%) were seen to source domestic water from the municipal pipe-borne water supply, while only 5\% source water from their own dug-in well only. 27\% of the households reported diarrhea in their household in the last six month. The diarrhea was found to have bivariate association with the number of children in the household, the educational level of the household head, and income of household head. No association was found between diarrhea and age of household head.

High premium should be placed on improving access to water and improved household hygiene as a way of helping to curb diarrhea.
\end{abstract}

\section{Introduction}

Water and sanitation has been identified as an important component of Primary Health Care (PHC) necessitating the World Health Organization to declare 1981-1990 as the international water years. ${ }^{1}$ However it is sad to note that though the world as whole has made tremendous progress in providing safe water for its teeming populace, the same cannot be said of the developing world especially Africa south of the Sahara. Nigeria been the largest single country in sub Saharan Africa is the worst hit with virtually three quarters of its population unable to access safe water. ${ }^{2}$ In most communities in Nigeria, domestic water is source from the river, well or rain water. A few urban communities are linked to pipe borne water which is treated from a central reservoir.

Water for domestic consumption needs to be managed properly to serve its intended purposes. Domestic water management simply refers to the act of rendering water safe for domestic consumption and will include proper sourcing, collection, transportation, treatment, storage, usage and all the good personal and environmental hygiene needed to make it clean. ${ }^{3}$ Any short coming in any of these steps will have serious health implications one of such is diarrhea disease. Diarrhea is defined as an abnormal increase in the daily stool fluidity, frequency and volume ${ }^{4}$ from what is considered normal for a particular individual. Diarrhea disease kills an estimated 2.5 million people each year, the majority being children under five years of age. ${ }^{5,6}$ It is responsible for over a quarter of the deaths of children in the world today ${ }^{7}$ most of which takes place in developing countries one of which is Nigeria where an estimated $25 \%$ of under five mortality is directly attributed to diarrhea disease. ${ }^{8,9}$

Despite the fact that health authorities generally accept that safe water plays an important role in preventing diarrhea episodes it is still sad to note that diarrhea is still an important cause of under five morbidity and mortality in Nigeria ${ }^{6-10}$ This then prompted the need for this study to establish the relationship between domestic water management practices and the prevalence of diarrhea in Tudun Wada Ward of Jos North LGA, Plateau State of Nigeria.

\section{Methodology}

This study was undertaken in Tudun Wada Ward of Jos North LGA,a semi urban municipality located on the highlands of the Plateau. Within its area of 3 square kilometers there are approximately 16000 inhabitants distributed amongst 5 communities. There is one Primary health centre (with a small Laboratory but no beds) and two smaller health posts and a handful of privately own clinics and maternity homes. A random sample of houses registered with the Ministry of health immunization census was visited in order to determine the prevalence of the different types of water supply and sanitation.

\section{Participants}

Selection criteria consist mainly of heads of households. A head of household was defined as the 
person responsible for decision making in the house hold, while a unit household was defined as a family living together and eating from the same pot.

\section{Instruments}

A semi structured interviewer administered questionnaire was used in generating data for analysis. All household heads were made to answer questions with regards to their age, family size, family type, highest educational attainment and income. In addition, information on the number and ages of children in the household and frequency of diarrhea in the last one year was obtained.

Each household head was also asked questions on the source and location of water for domestic use. Ethical approval was sought and obtained from the Jos University Teaching Hospital ethical committee while each house hold head gave a written informed consent before the study was conducted. All data generated was analyzed using Epi info version 3.5.2 software of the CDC.

\section{Results}

Socio demographic characteristics of households We surveyed 200 households in between June and July 2005 within a five week period. Fifty per cent (101) of the household heads were aged between 30-39 years, twenty six percent (52) between 40-49 years, twelve percent were between 20-29 years, nine percent(16) were between $50-59$ years, two percent (4) were aged 60 and above while one percent (2) had teenage head of household. Table1. We also notice that fifty eight percent (115) of the household heads had secondary education, eighteen percent (37) had tertiary education, and sixteen percent (32) had primary education while nine percent (16) had no formal education. Table2.

Most of the households were noticed to source their water from the municipal pipe-borne water only $(80 \%)$, fourteen percent source from both well and pipe-borne supplies, two households $(1 \%)$ use only well water while five percent (10) source from all three supplies. Table3.

Diarrhea was noticed to occur in twenty seven percent (53 households) while seventy three percent (147) of the households reported no diarrhea.

Relationship of diarrhea with certain risk factors Table 4 shows the results of testing the association of five factors with the development of diarrhea in the households. Diarrhea is seen to have bivariate association with number of children in the household, source of domestic water, domestic water treatment, educational status of household head and income of household head. No association was found between diarrhea and age of household head. Only three variables reached the statistical significance level $(\mathrm{P}<0.05)$ in the logistic regression multivariable model predicting diarrhea. Number of children in the household (OR 0.27, 95\% CI: 0.11 0.64 ), source of domestic water (OR $0.23,95 \%$ CI:.00-0.86), and educational level of household head (OR 4.09, 95\% CI :1.30-13.08).

Table 1: Age Characteristics of household heads

\begin{tabular}{|c|c|c|}
\hline Age of household head & Frequency & $\%$ \\
\hline$<20$ yrs & 2 & 1 \\
\hline $20-29$ yrs & 24 & 2 \\
\hline $30-39$ yrs & 101 & 50 \\
\hline $40-49$ yrs & 52 & 26 \\
\hline $50-59$ yrs & 16 & 9 \\
\hline$>60$ yrs & 4 & 2 \\
\hline
\end{tabular}

Table 2: Educational levels of household

Variable

\begin{tabular}{lcc} 
Variable & Frequency & \% \\
\hline Primary education & 32 & 10 \\
Secondary education & 115 & 58 \\
Tertiary education & 37 & 18 \\
No formal education & 16 & 9
\end{tabular}

Table 3 : Source of domestic water

\begin{tabular}{lll} 
Variable & Frequency & \% \\
\hline Pipe-borne water & 160 & 80 \\
Well water & 2 & 1 \\
Bore hole & 28 & 14 \\
All three sources & 10 & 5
\end{tabular}

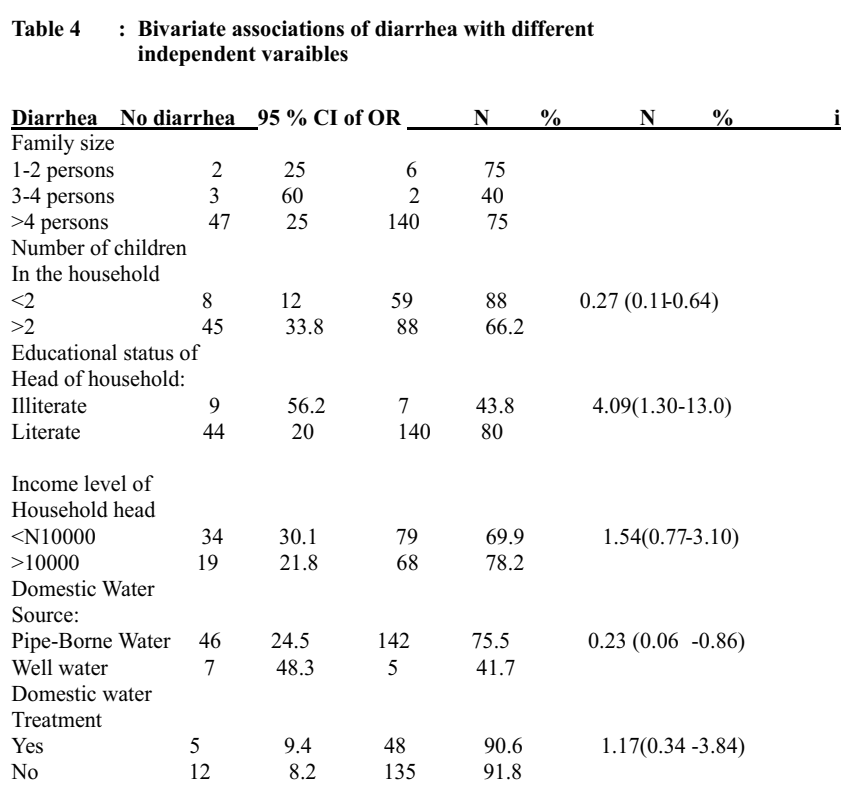




\section{Discussion}

This study examined and analyzed domestic water sourcing and the risk of diarrhea in a crosssectional study of households in a peri- urban community.

Our findings support the notion that access to water is an important risk factor for diarrhea. Mertens et al ${ }^{11}$ working in Sri Lanka were able to demonstrate that diarrhea morbidity was significantly related to the type of water source as found in our study. This effect was adjudged to be due to water quality rather than water availability. However in our study, we found an increased incidence of diarrhea morbidity in those who use pipe-borne water. Even though pipe-borne water is said to be safer than other sources of water, our findings may not be unconnected with the fact that most of these homes actually source for pipe-borne water outside their home with an increased risk of contamination because of distance and possibly contamination at source. This was corroborated by Gorter ${ }^{12}$ et al who demonstrated that water sourcing five hundred meters away from the home is associated with increase diarrhea morbidity as a result of microbial contamination.

We also found an association between the level of education of the household head and increase incidence of diarrhea morbidity. This may not be unconnected with better hygiene and sanitation practice that education confers on a person especially the mothers. ${ }^{13,14}$

A significant association was found between the number of children in the household and the risk of diarrhea. The higher rate of diarrhea morbidity in houses with more children under the age of five requires little explanation. Secondary transmission of diarrhea is obviously facilitated by person to person contact between the children in the house. ${ }^{15}$ Family planning programmes or improved housing may have some impact on diarrhea incidence. ${ }^{16,17,18}$

\section{Conclusion}

This study suggest that diarrhea morbidity is associated with water-washed factors and so suggest a higher premium on improving access to water as a measure to curbing diarrhea in the community.

It also does suggest that improvements in water availability and hygiene education can be effective interventions for the prevention of childhood diarrhea.

\section{Reference}

1. Howard G, Bartram J (2003) Domestic water quantity, service level and health. Executive summary. Geneva, W o r l d H e $1 \mathrm{th} O \mathrm{O}$ g a n i z a t i o $n$ http://www.who.int/water_sanitation_health/diseases/w sh0302/en

2. WHO, UNICEF (2006) Meeting the MDG drinking water and sanitation target. The urban and rural challenge of the decade. Geneva, World Health $\begin{array}{llllllllllll} & \mathrm{r} & \mathrm{g} & \mathrm{a} & \mathrm{n} & \mathrm{i} & \mathrm{z} & \mathrm{a} & \mathrm{t} & \mathrm{i} & \mathrm{o} & \mathrm{n}\end{array}$ http:/www.who.int/water sanitation health/monitorin g/jmp2006/en/index.html

3. Sobsey DM. Managing water in the home: accelerated health gains from improved water supply. Geneva: World Health Organization, 2005.www.who.int/water sanitation-health/dwq/wsh0207/en (accessed 16Aug 2005).

4. Martines J, Phillips M, Feachem RG. Diarrhoeal diseases. In: Jamison DT, Mosely WH, Measham AR, Bobdadillia JL (eds). Disease Control Priorities in Developing Countries.

Oxford: Oxford University Press, 1993.pp. 91116.

5. Kosek M, Bern C, Guerrant RL. The global burden of diarrhoea disease, as estimated from studies published between 1992 and 2000. Bull WHO 2003;81:197-204.

5 Mintz ED, Reiff FM, Tauxe RV. Safe water treatment and storage in the home: a practical new strategy to prevent water-borne disease. JAMA 1995;273:948-53.

6. Huttly SRA, Blum D, Kirkwood BR, Emeh RN, Feachem RG. The epidemiology of acute diarrhoea in a rural community in Imo State, Nigeria. Trans R Soc Trop Med Hyg 1987;81:865-70.

7. Ekanem EE, Akitoye CO, Adedeji OT. Food hygiene behaviour and childhood diarrhoea in Lagos,Nigeria: a case-control study. J Diarrhoeal Dis Res 1991; 9:219226.

8. Babaniyi OA. Oral rehydration of children with diarrhoea in Nigeria: a 12-year review of impact on morbidity and mortality from diarrhoeal diseases and diarrhoeal treatment practices. J Trop Pediatr 1991; 37:57-63.

9. Oni GA, Schumann DA, Oke EA. Diarrhoeal disease morbidity, risk factors and treatments in a low socioeconomic area of Ilorin, Kwara State, Nigeria. J Diarr Dis Res 1991; 9:250-257.

10. Ekanem EE, Adedeji OT, Akitoye CO. Environmental and behavioural risk factors for prolonged diarrhea in Nigerian children. J Diarrhoeal Dis Res 1994; 12:19-24.

11. Mertens TE, Fernando MA, Cousens SN et al. (1990) Childhood diarrhoea in Sri-Lanka: a case-control study of the impact of improved water sources. Tropical Medicine and Parasitology 41, 98104.

12. Goter AC,Sandiford P, Smith GD, Pauw JP.Water supply, Sanitation and diarrhea disease in Nicaragua: Results from a case-control study. Int J Epid, 1991;20:527-533.

13. Grosse RN, Auffrey C. Literacy and health status in developing countries. Ann Rev Public Health 1989; 10: 281-97.

14. Dargent-Molina P, James SA, Strogatz DS, Savitz DA. Association between maternal education and infant diarrhea in different household and community environments of Cebu, Philippines, Soc Sa Med 1994:38:343-350. 
15. Knight SM, Toodayan W, Caique WC, Kyin W, Barnesa A, Desmachelier P. Risk factors for the transmission of diarrhoea in children: a case control study in Malaysia. Int J Epidemiol 1992;21:812-8.

16. Bern C, Martines J, de Zoysa I, Glass RI. The magnitude of the global problem of diarrhoeal diseases: a ten-year update. Bull World Health Organ 1992;70:70514.
17. World Health Organization. The World Health Report 2002: Reducing Risks Promoting Healthy Life. Geneva: World Health Organization, 2002.

18. Quick RE, Kimura A, Thevos A, Tembo M, Shamputa I, Hutwagner L, et al. Diarrhoea prevention through household-level water disinfection and safe storage in Zambia. Am J Trop Med Hyg 2002;66:584-9. 